\title{
Research on Approaches and Significance of Great Wild Goose Pagoda Tourism under the Guidance of "the Belt and Road" Strategy
}

\author{
Zhongtao Hui \\ Department of Sports \\ Xi'an University of Science and Technology
}

\author{
Biliang Zeng \\ School of Marxism \\ Xi'an University of Science and Technology
}

\begin{abstract}
Great Wild Goose Pagoda tourism is a brand industry of Xi'an city and Shaanxi Province. However, for a long time, the tourism of Big Wild Goose Pagoda has been confronted with many difficulties in development. "the Belt and Road" strategy is an important measure that China and the Party proposed to promote social economy development. Since implementation of "the Belt and Road" strategy, the whole Xi'an people actively respond to the strategy and realize the transformation and upgrade of the tourism of Great Wild Goose Pagoda by developing in-depth tourism products and highlighting competitive products, etc. The transformation and upgrade boosts the social economy development of western China and relevant regions, and Big Wild Goose Pagoda tourism has gradually become an important pillar industry that promote the economy development of Shanxi and Xi'an and also a satisfying modern service industry.
\end{abstract}

Keywords-“the Belt and Road"; the tourism of Great Wild Goose Pagoda; development approaches

\section{INTRODUCTION}

Great Wild Goose Pagoda (GWGP) tourism is an important industry to the economy development of Xi'an city and Shaanxi province. For a long time, Xi'an city has been developing slowly in social economy, on account of the location in the inland of China and the relatively conservative minds. GWGP tourism has not contributed too much to the economic society of Xi' an city and Shaanxi province. Since the 18th National Congress of the Communist Party of China, China and the Party proposed "the Belt and Road" (B\&R) strategy to promote the development of economic society of western China. In addition, led by the $B \& R$ strategy, the GWGP tourism has been developing stably and enters into a new development age by developing in-depth tourism products and highlighting competitive products, etc.

\section{DEVELOPMENT STATUS OF GWGP TOURISM}

The GWGP was built in the third year of Yonghui administration of Tang Dynasty (652 A.D.) for the Monk Xuanzang to bring the Buddhist texts and Buddha statues from India via the ancient Silk Road. Standing in silence, the GWGP

This paper is a result of the research of the integration of Chinese dream into the ideological and political education of Tibetan college student of western regions (Project grant no: 14XKS035). has witnessed the changing history of northwest China for over a thousand years. As the most ancient and largest brick tower with quadrate pavilions built in Tang Dynasty, the GWGP is the great witness of pagoda that as the typical building type of Buddha temples gradually integrates into Chinese culture with spread of Buddhism in China. In addition, containing the wisdom of Chinese people, the GWGP is also regarded as the symbol of the ancient capital Xi'an city and Shaanxi province. As the treasures of the Chinese culture, it is a precious cultural tourism resource that plays an important role to boost the development of the city, and it is also the eastward extending endpoint of the Silk Road. Nevertheless, for a long time, there is a sharp contrast between the glorious history of the GWGP and the inland economy that is the big environment it is in. That is to say, the two roles it plays do not match each other, as the city's cultural name card and as a booster of the development of the city. In this case, the development of the times calls on implementation of new measures.

Since the new century, the Party and country put forward "west region development strategy" to drive the comprehensive development of the economic society of western China and Xi'an city. However, the GWGP tourism shows its weakness when comparing with the economic benefit of other world cultural heritage. Since the 18th National Congress of the Communist Party of China, the B\&R strategy was proposed by the Party and country to narrow the gap between the western and eastern regions of China so as to achieve the common prosperity. As we all know, $B \& R$ is the abbreviation of the "the Silk Road Economic Belt" and "the 21st-Century Maritime Silk Road" and is the extension and expansion of the ancient Onshore Silk Road and Maritime Silk Road. The B\&R "will rely completely on the existing bilateral and multilateral mechanism between China and the relevant countries with the help of the existing and effective regional cooperation platforms. Using the history sign of the Ancient Silk Road, the B\&R holds high the banner of peace development and actively develops the economic and cooperative partnership with the countries along the Belt and Road to build a community of shared interests, destiny and responsibility featuring mutual political trust, economic integration and cultural inclusiveness". ${ }^{1}$ As national and regional policies about the B\&R are released,

\footnotetext{
Put forward by the president of China Xi Jinpin in the speech in Nazarbayev University in Kazakhstan in 2013.
} 
they drive the development of primary and secondary industries and provide new opportunity to the innovative development of regional tourism at the same time. The ancient Silk Road mainly passed through the western regions of China such as Shaanxi province, Gansu province and Sinkiang, and the rebuilding of the $\mathrm{B} \& \mathrm{R}$ brings a historic opportunity to the development of these western regions. The $\mathrm{B} \& \mathrm{R}$ is abound to improve the infrastructure and develop the superior resources of northwest regions and even the western China, and open wider to the outside world so as to create a powerful support to the sustained and stable growth of the national economy.

\section{SPECIFIC COUNTERMEASURES FOR THE INTEGRATION OF THE B\&R STRATEGY INTO THE GWGP TOURISM}

Shaanxi province and Xi'an city need to make a proper and practical development program without delay according to the important instructions from the president $\mathrm{Xi}$ Jinpin and the development strategy of the Party and country. During the implementation of the 13th Five Year Plan, it is the main line and crucial support for Shaanxi province and Xi'an city to initiatively and comprehensively implement and integrate into the B\&R strategy so as to build all-round moderately prosperous society and to accelerate the construction of modernization developmental strategy. Tourism is the pillar industry for the social economy development of Shaanxi province, which is clearly demonstrated in the Implementation Plan of the Integration of the Belt and Road Strategy into the Development of Shaanxi Province. The plan clarify that as the central area of the tourism of Shaanxi Province, the GWGP is of great significance to make Shaanxi province a famous resort for tourists, by actively promoting the cooperation with the countries along the Belt and Road in tourism. ${ }^{(1)}$ Based on the aim proposed in the implementation plan and the long-term research, the GWGP tourism is supposed to promote the supply-side structural reform of tourism and to enrich the tourism product system based on the B\&R strategy conforming to the development law of the market. Additionally, the GWGP tourism needs to improve its service and transfer from the quantity expansion to "scale and quality" so as to achieve comprehensive promotion in the market, scale, brand and standards. In this way, the program is expected to make attribution to the transformation and upgrade and enhancement of the GWGP tourism during the integration into the B\&R.

Second, deep integration of the GWGP tourism and the internet industry. At present, "Internet Plus" is deeply affecting, changing and even subverting the survival and development of traditional tourism, making it a necessary way to the upgrade and development of the tourism. Under the background of "Internet Plus", big data, cloud computing, mobile internet technology can be used in the development of Shaanxi tourism to analyze the consuming psychology, behavior and the trend of customers to explore the methods of tourism's innovative development under the new background. In this way, the advantages of internet-based tourism enterprise is likely to be found out so as to get an overall grasp of the commercial operation mode, competitive mode and cooperation mode of

(1) Li Jianxin. The development of tourism based on "the Belt and Road" [N]. China Tourism News, August 8, 2015. current tourism market to promote the informatization, digitization, the connection with the internet and internationalization of the GWGP tourism. On the basis of the commercial atmosphere and historical content, the tourism products of GWGP shall be developed and turn into productivity with the help of the internet.

Third, crossover integration of the GWGP tourism and urbanization. In recent years, tourism has performed well as a people-enriching industry and though highly of by people. Therefore, the function of tourism of employment promotion and income increase shall be fully exerted. The tourism industry needs to be developed to make attribution to country construction, living standards promotion of tourism towns and social economy development. Additionally, it is also a peopleenriching industry that helps poverty-stricken areas to alleviate poverty and acquire wealth to accelerate the course of an allround well-being society and to create material basis for the traveling of the residents there. To achieve this purpose, we should combine the GWGP-centered tourism industry and other relevant industries to create different platforms to employment for human resources and make contribution to the stable development of the society.

Last but not least, deep integration of the GWGP tourism and the cultural industry, the Silk Road is not only a commerce road but also a culture road. The president Xi Jinpin proposed to "promote people-to-people exchanges including education, tourism, academic level and arts of China and the countries along "the Belt and Road" to make them reach a new level". Depending on the profound historic culture, the tourism of Shaanxi province can initiate international communication and cooperation and co-build the Silk Road with the countries along "the Belt and Road". Under the opportunity of historical and modern industry, the GWGP is expected to make attribution to the culture-oriented commerce.

\section{THE SIGNIFICANCE OF THE ACTIVE INTEGRATION OF} THE GWGP TOURISM INTO “THE BELT AND ROAD” STRATEGY

The active integration of the GWGP tourism into "the Belt and Road" strategy can drive the development of the economic society of $\mathrm{Xi}$ 'an city and Shaanxi province and even the whole western region of China, and this is of great significance in theory and practice.

Above all, facilitating the achievement of the strategic target of "connecting the west and the east". Shaanxi is a major tourism province which has large outing groups and is also an important tourist destination. Under the guidance of "the Belt and Road" strategy, the advantages of geography, transportation and policy should be fully taken in the tourism cooperation. On one hand, based on the current status of Shaanxi tourism, the GWGP tourism needs to intensify cooperation with the cities along "the Belt and Road" by drawing lessons from the important instructions that the president Xi Jinpin gave to Henan tourism and the gist of the International Conference of Mayors of Tourist Cities held in Zhengzhou city. On the other hand, taking the advantage of Shaanxi as a transportation junction, Shaanxi should be made into a gathering and distribution place for local and foreign tourists so as to facilitate the tourists' traveling to the countries 
and regions along "the Belt and Road". In addition, the GWGP can utilizes or gets convenient immigrant policy and drawback policy for foreign tourists combining with other superior resources to attract tourists from the countries along "the Belt and Road" to Shaanxi and then to other places of China. The GWGP tourism is supposed to catch the opportunity to lay a solid foundation of the transformation and upgrade in the cultural and economic aspects. Besides, practical strategies are required in order to realize the transformation and upgrade of the GWGP tourism under the background of "the Belt and Road".

Next, realizing the integration of inland economy into national development strategy. In recent years, responding the national development strategy, the GWGP tourism pays more and more attention to overseas marketing activities to help tourism enterprises "go out", and creates a serial of well-known GWGP-based brand industries. At present, centering on the tourism belt along "the Belt and Road", the GWGP tourism makes the best of relevant national supportive policy and joins the promotion alliance of the Silk Road based on the new joint promotion method. Additionally, in order to raise the influence of Xi'an city and even that of the whole western China, a tourism group "the Silk Road" was built and an overseas office was set up, and meanwhile, encouraging competitive tourism enterprises to establish an overseas subsidiary corporation.

Additionally, realizing the integration of urban and rural areas. Since the reform and opening up, Chinese economic society has been developing rapidly and the comprehensive national power has been greatly enhanced, accompanying some problems such as large urban-rural gap. Aiming to figure out the "Lewis turning point", the GWGP tourism connects urban and rural areas and realizes a stable income increase of urban residents, laying a solid foundation of the integration of city and countryside.

Lastly, setting a good example for the transformation of western regions from the traditional society to modern society. With the transformation and upgrade of the GWGP tourism, the existing tourism resources are integrated and tourism industry is established, centering on the commercial and cultural activities of the regions relating to "the Belt and Road". For instance, with the historical culture tourism zone as the bond and national-level cultural industry park and intangible cultural heritage as the platform, the tourism of the Silk Road as the world cultural heritage was prioritized, in which modern science and technology and socialist culture integrate into the Buddha culture and Tang Dynasty culture. In addition, the exhibition area of Buddha culture and Tang Dynasty culture, together with Tang Dynasty culture-concentrated exhibition and experience zone are promoted. Besides, cooperation between Xi' an city and the cities along the Silk Road economic belt needs to be deepened. In a word, these measures provide a new way for the transformation of western regions from traditional society to modern society.

\section{CONCLUSION}

The integration of the GWGP tourism of Xi'an city into "the Belt and Road" strategy responses the call of the development of times and is the key point to realize the development goal under the background of the New Normal. It is made clear that the GWGP tourism is characterized by diverse resources with high grade, clear position, etc. although facing various challenges, the GWGP tourism receives many opportunities driven by "the Belt and Road" strategy. As a necessary and urgent subject of the times, the transformation and upgrade of the GWGP tourism is bound to boost the development of the local economic society, and this can be realized through its integration into "the Belt and Road".

\section{REFERENCES}

[1] Cheng Yao, Core Connotation and Implementation Approach of "the Belt and Road" [J]. China Development Observation, 2015(1).

[2] Wei Jiufeng, Research of Tourism Development of Henan Province in the Perspective of "the Belt and Road" strategy [J]. Shanxi agriculture and economy, 2016 (2). 